We try to publish authors' responses in the same edition with readers' comments. Time constraints might prevent this in some cases. The problem is compounded in a bimonthly journal where continuity of comment and redress are difficult to achieve. When the redress appears 2 months after the comment, 4 months will have passed since the article was published. Therefore, we would suggest to our readers that their correspondence about published papers be submitted as soon as possible after the article appears.

\section{Towards a Simpler Solution}

To the Editor: In response to Dr. Geyman's article (Family Practice in a Failing Health Care System: New Opportunities to Advocate for System Reform. J Am Board Fam Pract 2002;15:407-15), a rallying cry for a national, government-controlled, single-payer system, we would offer an alternative step toward a much simpler solution for health care reform. It is called SimpleCare.

Here is how SimpleCare works: Patients pay a small annual administrative fee ( $\$ 20$ per individual or $\$ 35$ per family) and then pay their providers at the point of service. Because providers eliminate costs associated with producing insurance claim forms, coding diagnoses and procedures, referrals, authorizations, payment delays, EOB reviews, claim denials, resubmissions, collection risks, and other managed care costs, they offer patients a "fair price" for services without the administrative hassles and bureaucracy. According to the SimpleCare Web site (http://www.simplecare.com), many physicians reduce their standard billed charges $30 \%$ to $50 \%$ for SimpleCare patients and benefit financially. To protect patients fully in case of a medical emergency that would result in financial disaster, SimpleCare should be combined with a high-deductible, major, catastrophic health insurance policy.

SimpleCare has a number of advantages: (1) it is provider and patient driven rather than being driven by the insurance industry or government, (2) which avoids bureaucracy and socialized anything, (3) leading to considerably reduced health care costs, (4) while empowering patients with choice of provider and services, (5) yet retaining market constraints that encourage patient responsibility for seeking service and fair prices from providers when charging for services. (6) Additionally, the minimal annual fee allows small businesses to provide some health care benefit for their workers and is likely affordable for the "working poor," who have no workrelated health benefits but earn too much to qualify for government aid.

We realize that SimpleCare system is not a panacea for all our ailing health care system woes. SimpleCare is an excellent idea for helping the millions of uninsured Americans afford health care. There are still important issues that need to be addressed, such as coverage for prescription medications and the role of a government safety net for those who cannot, by unfortunate circumstance or poor decision making, afford even fair market prices for health care. The roles of Medicare and Medicaid need to be reconsidered in respect to the latter issue. We would also argue that in addition to switching to a much more efficient system, such as SimpleCare, other systemwide reforms are mandatory to reduce the burden of health care expenditure, the foremost being prompt tort reform that limits damages in malpractice suits. Another useful reform would be to allow everyone the opportunity to contribute to a medical savings account and to carry over any balance for the next calendar year, if unused.

Although any transition will have difficulties that need to be worked through, and although no system will benefit everyone as they would like, we remain optimistic that health care reform can benefit both patients and providers and decrease bureaucracy

Eric Enberg, MD

Dan Swartz, MD

Family Medicine Residency Program Mercy Medical Center-North Iowa

Mason City, Iowa

\section{Esophageal Foreign Body vs Asthma}

To the Editor: Foreign body aspiration and ingestion in adults and in children have a variety of clinical symptoms and can be unrecognized for some time. ${ }^{1}$ The peak incidence of foreign body aspiration occurs during the second year of life in children and during sixth decade in adults. $^{2}$

Foreign body ingestion and aspiration in the pediatric population can cause wheezing and be diagnosed and treated as bronchial asthma by the primary care physician. ${ }^{3,4}$ We have had many children come to our institution and undergo radiographic examination for an unrelated medical condition, only to reveal an esophageal foreign body.

We describe an 11-month-old patient who was treated for bronchial asthma for several weeks. He came to the ear, nose, and throat clinic with a history of snoring and acute recurrent otitis media. A lateral neck radiograph to evaluate adenoid size showed a metallic foreign body at the thoracic inlet. A detailed history disclosed that the child had a wheeze and had been treated for asthma within the month before his clinic visit. The parents related the possibility of coin ingestion a few weeks earlier. After an endoscopic removal of the coin, the symptoms of asthma disappeared. Partial or even complete esophageal blockage with superimposed edema of the esophageal wall and adjacent tracheal tissue can mimic symptoms of asthma. Additionally, esophageal wall edema can cause pooling of secretions, which can lead to aspiration with worsening symptoms. 
We suggest that if ingestion of a foreign body is suspected in a pediatric patient, the child should be completely evaluated, including a chest radiograph, before labeling the symptoms to be due to asthma.

Abid U. Ghafoor, MD

Saif M. Siddiqui, MD

James F. Mayhew, MD

Department of Anesthesiology

Robin A. Dyleski, MD

Department of Otolaryngology

Samiya Razzaq, MD

Department of Pediatrics

Arkansas Children's Hospital

Little Rock

\section{References}

1. al-Majed SA, Ashour M, al-Mobeireek AF, al-Hajjaj MS, Alzeer AH, al-Kattan K. Overlooked inhaled foreign bodies: late sequelae and the likelihood of recovery. Respir Med 1997;91:293-6.

2. Baharloo F, Veyckemans F, Francis C, Biettlot MP, Rodenstein DO. Tracheobronchial foreign bodies: presentation and management in children and adults. Chest 1999; 115:1357-62.

3. Shneider BM, Khorov OG. [Esophageal foreign body in a child simulating the clinical picture of bronchial asthma.] Vestn Otorinolaringol 1987;1:70-1.

4. Puig-Abuli M, Rodriguez da la Nuez A, Arcas-Meca R, Villa Elizaga I. Esophageal foreign body as a cause of respiratory symptoms. Acta Paediatr Belg 1980;33:183-4.

\section{Improving Opioid Dependency Treatment}

To the Editor: Physicians have played an outsider role in the treatment of opioid dependency. We are called upon as the purveyors of authoritative signature when it comes to prescribing the controlled substances that are frequently used to replace illegal sources, and thus we contribute reluctantly to the drug diversion problem. We have been simultaneously prohibited from knowingly prescribing opiate agonist therapy for opioid addiction unless we are employed by one of 1,200 narcotic treatment programs that dispense methadone and levo-alpha acetylmethadol (LAAM). We are held responsible for treating the growing population of needle-use victims who have human immunodeficiency virus infection and hepatitis. We contribute through taxation to the burdensome and expensive systems designed to punish (but rarely rehabilitate) addicts and dealers, although hopeful is the idea of introducing methadone clinics into correctional settings.

Two and one-half million persons have used heroin in this country, and nearly 1 million do so currently. Approximately 1 in 5 are engaged in treatment. In that addictive medicine might be one of the quintessential subspecialties of family practice, given the solid evidence of genetic involvement in dependency disorders and the profound impact that substance abuse has on family function, it follows that the family physician might be an indispensable part of diagnosing and treating addiction in this large population.
A factor contributing to the gap between the problem and the solution (other than inadequate funding) is the stigma created by laws that criminalize the disease of addiction, most notably the Harrison Act of 1914 and the Narcotic Addiction Treatment Act of 1974. There is sound clinical, social, and medical-economic literature to support the integration of addiction treatment into the flow of primary care along with other preventable and treatable chronic illnesses. It was this body of evidence that led to the Drug Addiction Treatment Act of 2000. This legislation paved the way for qualified physicians to prescribe effective and approved medications for opioid dependency. It also allowed addicts to obtain therapy outside the existing restrictive and limited resources. It even allows for addicts to get care from their own physician!

Buprenorphine is a partial opioid agonist with a milligram-to-milligram equivalency to 30 milligrams of morphine. It has been available as a pain medication for years. Because of its high affinity for opioid mu receptors and its long duration of action, buprenorphine was recognized as a potential blocking agent and has been used in Europe as an alternative to methadone. Because of additional pharmacologic benefits (one of which is how hard it is to overdose on), it was approved by the Food and Drug Administration (FDA) in October 2002 for use in the treatment of opioid addiction.

Buprenorphine is currently available in two sublingual forms-Subutex and Suboxone (mixed with naloxone). The latter, if altered and used intravenously, can precipitate an acute opiate withdrawal syndrome in an actively using, opiate-dependent patient. By itself, buprenorphine can also trigger an abstinence syndrome unless it is used after the natural onset of craving, in which case it relieves withdrawal symptoms. Obviously, these medications are tools to be used only by those who know what they are doing. An excellent review article on the use of buprenorphine in office-based opioid dependency treatment was published in the 12 September 2002 edition of The New England Fournal of Medicine.

The Drug Addiction Treatment Act and FDA approval of buprenorphine offer great opportunities for family physicians to play dynamic and proactive roles in the treatment of a common disease. We have an opportunity to treat pain and addiction in harmony, not competitively. Collaboration with regulatory agencies (Federation of State Medical Boards and National Association of Boards of Pharmacy) and in-the-trenches clinicians (American Society of Addiction Medicine) has already been a challenge for the federal bureaucrats and scientists (Center for Substance Abuse Treatment). Now is a great opportunity for all of the above to combine efforts with our state health departments and schools of medicine in adopting this new paradigm and avoid the tragic results that followed the release of "hillbilly heroin." We have an opportunity to draw more addicts into the recovery milieu.

A detailed list of the criteria required for the waiver that allows for use of these medications is available at 
http://www.buprenorphine.samhsa.gov. Briefly, waivers are granted to licensed physicians who document a minimum of 8 hours of education by an approved trainer. Each physician may treat no more than 30 opioid addict patients at a time. An additional requirement is the capacity to refer to other treatment modalities so that more holistic approaches are used. A list of the certified physicians is also available at the above Web site.
Getting the treatment of opiate addicts out of the closet and into the clinic has been a long-awaited process. Physicians can participate with cautious empowerment in this new arena, and while doing so, they can reduce the suffering of our patients and their communities.

Jaye T. Swoboda, MD New Mexico Monitored Treatment Program Albuquerque 